\title{
Children Affected by Trauma in Conflict Areas and Need for School-based Psycho-social Intervention
}

\author{
Bilal Kaloo ${ }^{1 *}$, Tanveera $\mathrm{Ali}^{2}$
}

\section{ABSTRACT}

An established fact is that in any armed conflict the bulk of the sufferers include women and children world-wide. The experience and exposure of children to violent incidents hampers their well being. Trauma caused by such violent incidents becomes threatening if not addressed properly and on timely basis. The role of family, community and other stake holders to relieve traumatized children in strengthening their coping mechanism is imperative. Teachers including school personnel usually develop trusting relationships with children and parents .Teachers may allocate time to deal with traumatic experiences, model the children's responses, reinforce emerging coping skills and help children to resume normal life. Committed and trained teachers may turn out to be excellent mediators to provide mental health relief to large groups of children affected by trauma. This literature review analyses the importance and effectiveness of teachermediated psychosocial preventive interventions among children traumatized in the context of armed conflicts (war, military violence, and terrorism).

Each child reacts differently to the impact of armed conflict. Their response depends on their age, gender, personality type, personal and family history, cultural background and experience, as well as on the nature and duration of the event. Stress can reveal itself in a wide range of symptoms, including increased separation anxiety, developmental delays, sleep disturbances, nightmares, flashbacks, decreased appetite, withdrawn behavior, and a lack of interest in play. Younger children can have learning difficulties; older children and adolescents can show anxious or aggressive behavior and depression. Parents, teachers and community networks must be mobilized to provide the continuity, trust and stability children need for recovery. This paper explains how important is the teacher mediated intervention in reaching out to children affected by trauma in conflict situations.

Methodologically: Apart from the related literature review, the paper contains inferences from authors experience while working as mental health counselor in Kashmir, India.

Keywords: Children, Conflict, Trauma, Schools, Psycho-Social Care.

Researchers agree that traumatic events involving life-threat, helplessness and horrifying scenes contribute a risk to mental health and developmental problems among children (Ehntholt KA,

\footnotetext{
${ }^{1}$ Assistant Professor, Faculty of Education University of Kashmir, India

${ }^{2}$ Ex-Counsellor, MSF-Holland, Kashmir Project, India

*Corresponding Author

(C) 2015 I B Kaloo, T Ali; licensee IJIP. This is an Open Access Research distributed under the terms of the Creative Commons Attribution License (http://creativecommons.org/licenses/by/2.0), which permits unrestricted use, distribution, and reproduction in any Medium, provided the original work is properly cited.
} 
Yule W. 2006).Children affected by conflict usually have traumatic experiences about the incidents that they directly or indirectly experience or witness. Disasters natural or man-made including the armed conflict have resulted in tremendous loss of death and destruction. The mental health of the sufferer is ignored in general and that of children in particular. As bulk of the focus in such emergency situations goes to immediate relief and rehabilitation and the short term needs of survival become the priority. In the long run, intervention for remedial measures of traumatic stress among the victims remains unattended leading to maladjustment and failure to cope with the future. Despite the numerous advantages in implementing school-based interventions after a trauma or a disaster, particularly those mediated by teachers, only a few articles have been published on this subject. This paper reviews the relevant literature and offers a conceptual framework for implementing teacher-mediated mental health intervention programs among school-age children.

Mental health interventions are known to prevent the progressive worsening of symptoms in young victims of disaster, and, subsequently, to prevent a decline in their academic performance and self-esteem (Goenjian A et al 1997). However, the tremendous needs that emerges after a disaster and the reluctance shown by most victims to seek professional help require mental health leaders to adopt a proactive stance and to implement relief programs in the child's most natural setting. The school as institution and the teachers as empowered mediators offer the appropriate conditions for implementing an effective large-scale intervention program.

In the case of a mass disaster, as opposed to a limited traumatic event, the development and implementation of psychological interventions ought to draw on an understanding of the disaster syndrome. This syndrome includes massive individual and social losses (e.g., physical, economic, material, functional, social) and a clinical picture consisting of grief, dissociation and specific posttraumatic symptoms that may last for months or even years (Laor N, Wolmer L 2002).

Effective treatments for traumatized children usually involve cognitive-behavioral elements, including the psycho education of both children and parents regarding the nature of the disorder, some form of exposure work coupled with imagery or relaxation exercises, and a restructuring of cognitive dysfunctions (Laor. N 2001, 2002)

A recent follow-up of children and adolescents one year after their exposure to war trauma has shown that specific and non-specific classroom-based interventions using debriefing and cognitive-behavioral techniques were similarly effective (Fayyad. J et al 2002).

Comprehensive management of the enormous psychosocial needs within a community of children after a disaster requires that ordinary mental health service-delivery practices be complemented by endorsing a preventive public health perspective. This perspective prescribes adaptations in parameters such as setting (from office to school), format (from individual to 
group/class) and length (from long- to short-term), as well as modifications in the teacher's professional role.

The timing of the implementation of school-based interventions depends on the availability of professional resources, appropriate programs and housing for these programs. These interventions are preventive in nature, and are geared toward the psychological relief of the children as well as the reactivation and revitalization of the school as an instit

\section{Mental Health Intervention in Schools}

Teachers and school administrators tend to see the schools as educational centers, whereas they view hospitals, mental health clinics and trauma centers as treatment facilities for those exhibiting the psychopathological consequences of a disaster. This view may hold for the most severely affected victims. After a disaster, however, the great majority of children exhibit moderate levels of symptomatic responses, which are stressful but at the same time manageable. For these children, social, educational and practical considerations prescribe that the school is the most appropriate place for intervention. Klingman A (1993) underscored the unique role that schools may play in responding to this challenge. Aside from the family, school is a child's most natural support system, having a traditional formal status in society. School personnel usually develop trusting relationships with children and parents, and most are ready to be educated to serve a therapeutic role (Vernberg EM, Vogel JM 1993).

Moreover, support from classmates and teachers have been recognized as a significant predictor of fewer posttraumatic symptoms after a major disaster. Such support prevents withdrawal and isolation (Pynoos RS, Nader K. 1988).

Debriefing may be an efficient tool to help children and adults (Stallard P, Law F. 1993). However, in some individuals very early exposure to the memory of a traumatic event may interfere with the normal affective-cognitive processes that lead to their recovery, resulting in neutral effects or even in an exacerbation of symptoms (Wessely S, Rose S, Bisson J. 1998).

Through empowerment, teachers may be helped to adopt and exercise a transformational leadership position (Bass B M, Avolio B J 1994) that can be translated practically into (i) formulating a vision (e.g., "regaining our strength and excelling in academic achievements"); (ii) providing individualized consideration (being sensitive to the individual needs of children and parents); (iii) fostering an atmosphere of stimulating cognitive and creative processes (intellectual coping that supports initiatives); and (iv) transmitting positive expectations (concerning the children's capacities and potential). Transformational leadership serves to restore the three existential dimensions damaged by disaster (Laor N. 1996): space (as the domain of human activity), time (that has been shrunk to a "continuous present"), and self (that has been defeated). 
Teaching in schools after disasters is a difficult task.Managing regular curriculum while at the same time integrating intervention programs for traumatized students requires teachers to invest enormous affective, behavioral, and cognitive resources. Therefore, the continuous support and supervision of the staff becomes a central component in any teacher-mediated intervention. Supervisors need to be aware of the larger context and dynamics of their own systemic intervention. If properly executed, supervision provides a much needed holding environment for teachers (Bostic JQ 2002) in which they are offered encouragement and mutual support and given an opportunity to analyze, share experiences and doubts, and discuss and collaboratively prepare mode of action for trauma affected children in school settings.

\section{Significance of School as a Social Institution}

Education has a major part of play in the response to any natural or man-made calamity and the role involves ordinary classroom teachers and situations. Some points to remember are:

I. School is a large part of a child's life. What happens there and what affects it is important to all. The school provides the main support and social network.

2. School is the normal place for a child to be and offers security at a time of insecurity. Trauma reactions are normal reactions and are best helped in a normal environment.

3. Children are in school in their own right, not because they have a problem or carry a 'survivor' or 'victim' label. This is important as survivors often feel a loss of power and dignity. Seeing a social worker or psychologist still carries a stigma and at school you have a choice about who you talk to.

4. The way adults respond to children can significantly affect the outcome of their experience; thus the reactions of teachers who they see daily are vital - the teachers need to be informed. Teachers often unwittingly cause more problems for children.

5. Teachers have known the children before the disaster and may see them for several years after. They are in a prime position to observe behavior changes, delayed shock and reactions which are not being resolved, and can make referrals.

6. Teachers have many skills and techniques which, with a little training and awareness, can be adapted to help children cope with trauma. These can be used in normal class lessons and will reach the many affected children who would not seek other help and those who can give support to their friends.

7. Such crises can provide opportunities for a great deal of real-life learning at a time when children want and need to find solutions. What is education for if it is not about real life?

\section{DISCUSSION}

The above research findings have highlighted the role of teacher in acting as a facilitator to come to the rescue of the children affected in any disaster. Armed conflict world over is posing to be the worst man-made disaster is denying the children from a safe and secure environment. Frequent incidents of violence in armed conflict areas have victimized millions of children directly and indirectly. 
The psychological damage incurred upon children due to armed conflict has been extensively reported in number of research studies.

Children affected by armed conflict may exhibit both acute and chronic reactions, both of which are normal responses to highly stressful events. Prominent among the acute psychological disturbances is trauma, which is typically associated with problems of flashbacks, nightmares and sleep disturbances, concentration problems, heightened alertness or hyper vigilance, and avoidance of people and situations that evoke memories of the traumatic events. In diverse Western cultures, acute trauma coupled with these symptoms often falls under the clinical diagnostic Post-Traumatic Stress Disorder (PTSD). Children in war situations often face chronic, ongoing stressors such as poverty and that categories such as PTSD cease to have meaning under these conditions (Straker, Gillian, 1987). The chronic stresses associated with armed conflict may lead to problems such as aggression (Boothby, Neil, 1996), depression (Macksoud, Mona S. \& J. Lawrence Aber, 1996), truncated moral development (Ferguson, N, E Cairns,1996), changed attitudes and beliefs, and diminished hope for the future(Cairns, E 1996). The Machel Study recognizes that children's responses vary according to situational factors such as the intensity, quality, duration, number, and frequency of the stressors. Although children exposed to multiple stressors show greater psychological impact (Garbarino, James \& Kathleen Kostelny, 1996), the effects of violence vary according to the nature of the stressors and the role played by children . Children's resilience in the face of stress depends on protective factors [24] such as the presence of a well-functioning caregiver who can provide effective emotional support. Unaccompanied children, particularly under the age of seven years, are at much greater risk of psychological damage (Ressler, Everett M.; Neil Boothby \& David J. Steinbock, 1988).

\section{CONCLUSION}

In view of the above findings in the research reports, children's psychological well being in conflict areas is usually ignored. Trauma - that is universal among children in conflict affected areas needs to be addressed by the care givers on immediate basis. There is a dearth of mental health experts in general and in emergency situations like an armed conflict in particular. Whereas most of the studies point to the fact that the trauma at the initial stage among children in conflict zones is of low intensity rather than acute, and it aggravates as there is delay in timely intervention to treat such children at early diagnosis. The deficiency of health professionals during violent situations especially mental health experts exposes children with minor psychological ailments to greater vulnerabilities. Teachers can be utilized as a resource to come to the help of such children, provided they have some basic training in handling children with trauma related psychological problems. Teachers in a given community develop a trusting relationship with children in educational setting and thus exercise an influence on the children's development and well-being. This trust and influence can be channelized in the interest of the children that are in dire need of psycho-social support in conflict areas. 
Every conflict affected country cannot afford to provide services of qualified and experienced psychologists and mental health experts during conflict or post-conflict situations to large number of affected population. And again children as recipients of mental health care are taken for granted. Teacher-mediated intervention to treat such children as such provides some space to reach out to them when the options are limited. Teachers are to be seen as a resource in such crunch times, whose abilities and skills when given a 'support and back-up' can alleviate the sufferings of trauma affected children.

Capacity building of teachers in effectively dealing with trauma affected children can be useful in the long run. Incorporating the component of preliminary mental health care in teacher training programmes in areas affected by armed conflict is as such highly recommended. States usually have teacher training institutions that provide inputs to enrich them with skills to effectively deal with teaching learning problems. Teacher mediated intervention modules for helping traumatized children in conflict areas is much needed and has the potential to deliver good results. Both non-governmental organizations (NGO's) and international non-governmental organizations (INGO's) in this respect can act as a facilitating link to strengthen the teacher training institutions to bring innovations to build capacities of teachers to help traumatized children. Usually these organizations have been found active in natural calamities assisting governments in their relief and rehabilitation programmes. Some of these organizations have developed expertise in specific interventions like damage assessment, advocacy, emergency education, child rights and child protection, health issues etc.

Some states that have a prolonged history of conflict situations have contextualized their education system with the existing realities. As such conflict affected states cannot afford to ignore the influence of violence related incidents on the education system. In such contexts, teachers have to be trained adequately not only to bring effectiveness in teaching but also realize and respond to the needs of trauma affected children. This calls for an urgent need for advocacy and implementation of teacher mediated intervention in the educational policies of conflict affected states.

\section{REFERENCES}

Boothby, Neil, 1996. 'Mobilizing Communities to Meet the Psychosocial Needs of Children in War and Refugee Crises', in Apfel \& Simon (149-164).

Bostic JQ 2002 Consultation to schools about responses to disasters. [abstract 49C]. In: The scientific proceedings of the 49th Annual Meeting of the American Academy of Child and Adolescent Psychiatry. San Francisco p. 77.

Cairns, Ed, 1996. Children and Political Violence. Oxford: Blackwell.

Chemtob CM, Tomas S, Law W, Cremniter D. 1997 Postdisaster psychosocial intervention: A field study of the impact of debriefing on psychological stress. Am J Psychiatry 154:415417. 
Ehntholt KA, Yule W. 2006. Practitioner review: Assessment and treatment of refugee children and adolescents who have experienced war-related trauma. J Child Psychol Psychiatry 47:1197.

Fayyad J, Karam E, Karam A, Cordahi C, Mneimneh Z, Melhem N, 2002 Community group therapy in children and adolescents exposed to war. [abstract 43C]. In: The scientific proceedings of the 49th Annual Meeting of the American Academy of Child and Adolescent Psychiatry. San Francisco: p. 70.

Ferguson, Neil \& Ed Cairns, 1996. 'Political Violence and Moral Maturity in Northern Ireland, Political Psychology 17(4): 713- 725.

Garbarino, James \& Kathleen Kostelny, 1996. 'The Effects of Political Violence on Palestinian Children's Behavioral Problems: A Risk Accumulation Model', Child Development 67(1): 33-45.

Goenjian A, Karayan I, Pynoos RS, Minassian D, Najarian LM, .Steimberg AM, 1997 Outcome of psychotherapy among early adolescents after trauma. Am J Psychiatry 154:536-542.

Goenjian A. 1993 A mental health relief programme in Armenia after the 1988 earthquake: Implementation and clinical observations. Br J Psychiatry 163:230-239.

Klingman A 1993. School-based interventions following a disaster. In: Saylor CF, editor. Children and disaster. New York: Plenum Press; p. 187-210.

Laor N, Wolmer L 2002 Children exposed to disaster: The role of the mental health professional. In: M. Lewis, ed. Textbook of Child and Adolescent Psychiatry, 3rd ed. Baltimore: Williams and Wilkins p. 925-937.

Laor N. 1996 The protective matrix as risk-modifying function of traumatic effects in preschool children: A development perspective. 6th International Psychoanalytic Association Conference on Psychoanalytic Research. London

Laor N. 2001 The role of mental health professionals after mass disasters. Presented at the Congress on The Promised Childhood, Tel Aviv

Macksoud, Mona S. \& J. Lawrence Aber, 1996. 'The War Experiences and Psychosocial Development of Children in Lebanon', Child Development 67(1): 70-88.

Mayou RA, Ehlers A, Hobbs M 2000 Psychological debriefing for road traffic accident victims. Br J Psychiatry 176:589-593.

of post traumatic stress disorder. Cochrane Library (Vol 4). Oxford.Bass B M, Avolio B J 1994 Improving organizational effectiveness through transformational leadership. Thousand Oaks, CA: Sage Publications

Perrin S, Smith P, Yule W. 2000 Practitioner review: The assessment and treatment of posttraumatic stress disorder in children and adolescents. J Child Psychol Psychiatry 41:277- 289.

Pynoos RS, Nader K. 1988 Psychological first aid and treatment approach to children exposed to community violence: Research implications. J Trauma Stress 1:445-473.

Ressler, Everett M.; Neil Boothby \& David J. Steinbock, 1988. Unaccompanied Children: Care and Protection in Wars, Natural Disasters, and Refugee Movements. New York: Oxford University Press. 
Rutter, Michael, 1985. 'Resilience in the Face of Adversity: Protective Factors and Resistance to Psychological Disorder', British Journal of Psychiatry1 47(4): 598-611.

Stallard P, Law F. 1993 Screening and psychological debriefing of adolescent survivors of life threatening events. Br J Psychiatry163:660-665.

Straker, Gillian, 1987. 'The Continuous Traumatic Stress Syndrome: The Single Therapeutic Interview, Psychology and Sociology 8 (1): 48-79.

Vernberg EM, La Greca AM, Silverman WK, Prinstein MJ 1996 Prediction of posttraumatic stress symptoms in children after Hurricane Andrew. J Abnorm Psychol 195:237-248.

Vernberg EM, Vogel JM 1993. Interventions with children after disasters. J Clin Child Psychol 22:485-498.

Wessely S, Rose S, Bisson J. 1998 A systematic review of brief psychological interventions (“debriefing”) before the treatment of immediate trauma related symptoms and the prevention 